\title{
A vida originária: diálogo entre A Hora da Estrela de Clarice Lispector e a Fenomenologia da Vida de Michel Henry
}

\section{The originary life: dialogue between The Hour of the Star by Clarice Lispector and Michel Henry's Phenomenology of Life}

\author{
João Elton Jesus \\ Graduando, Curso de Filosofia, Faculdade de Filosofia e Teologia - FAJE, Belo Horizonte, Minas Gerais, \\ Brasil.
}

\begin{abstract}
Resumo: Este trabalho tem por objetivo apresentar dois pontos de vista que convergem para o mesmo sentido: a Vida. Para isso é apresentada a história de Macabéa, personagem de Clarice Lispector. Essa escritora, ao observar a realidade, percebeu o quanto a vida é obscurecida por um sistema social, econômico, cultural e político cada vez mais cruel e opressor. Michel Henry, por sua vez, tendo os mesmos sentimentos de Clarice, busca na fenomenologia a recuperação da Vida, que, embora sempre presente na existência humana, é vítima de um saber científico e de uma técnica que se dizem únicos detentores da verdade. Ambos buscam mover o leitor a uma reflexão sobre a existência, o que desencadeia em um pensar ético originário que leve em consideração a Vida em seu páthos, em sua afetividade, em sua imanência.
\end{abstract}

Palavras-chave: Barbárie; Cultura; Fenomenologia; Literatura; Vida.

Abstract: This article presents two points of view that converge into the same point: Life. Due to this, we present Macabea's story wrote by Clarice Lispector. This Brazilian writer, observing the reality, realized how life was obscured by social, economic, cultural and politics system increasingly cruel and repressive. Michel Henry, in turn, with the same feelings of Clarice, searches phenomenology recovery of Life, which, though always presents in human existence, is a victim of scientific knowledge and a technique that says only holders of the truth. Both thinkers draw readers toward a reflection about existence that brings an originary ethic considering life in its páthos, affectivity and immanence. Keywords: Phenomenology; Life; Culture; Barbarism; Literature. 


\section{Clarice Lispector}

Clarice Lispector (1920-1977) é considerada uma das maiores escritoras brasileiras. Em sua vida, conheceu diversas cidades e culturas. Com sua sensibilidade, captou os medos, as angústias, os sonhos e os sentimentos da condição humana. Para Yudith Rosembaum (2007) trata-se de "uma escritora que se dedicou a uma busca interminável: a representação do indizível, ou seja, do que não se pode representar em palavras dentro do código convencional da linguagem".

A autora de A Hora da Estrela buscava fazer em seus escritos uma leitura relevante. Esquivando-se da alienação, em suas personagens, a autora buscou revelar ao leitor a realidade e as problemáticas da vida. Segundo Para Abdala Jr. e Campedelli (2001, p.273), "longe de fazer uma literatura alienada, Clarice Lispector levanta justamente o cotidiano alienado. É a repercussão dele nas pessoas que a preocupa. Desse ponto de vista, seus livros são altamente comprometidos com o homem e com a realidade dele".

Nos diversos contos, romances e ensaios publicados, Clarice expunha a interioridade humana através de personagens do cotidiano. Para Bosi (2001, p.426), "o que a escritura de Clarice Lispector anuncia na esfera da ficção introspectiva dá-se também na do romance voltado para o horizonte social. Serão as vicissitudes do regionalismo em nossos dias". Assim, em cada palavra, história e metáfora, Lispector expressa a ausência de limite da verdade da vida em finitas folhas de papel.

Pela ótica formal, seus personagens vivem num mundo "opaco, caótico, raso por consequência, como efeito natural, reinando a estaticidade em suas relações". No entanto, existem momentos em que seus personagens se abrem numa sensação de vida ou na revelação de uma verdade fragmentada. É nessa tensão entre a opacidade e o instante liberador que se concentra o conflito básico da obra de Lispector. (SILVA, 2015)

A obra literária de Clarice não é de maneira alguma superficial. Através de suas histórias e personagens, ela apresenta o seu modo de fazer filosofia. É amiga da sabedoria e, portanto, da humanidade. Para Nunes (1966, p.43) o pensamento de Lispector não tem filiação doutrinária e se distingue do "terreno filosófico comum, convencionalmente chamado de existencialista, tem seu fulcro no primado da existência, individual e universal, primado esse que garante a tais correntes tão díspares, a unidade conceptual que efetivamente possuem".

Ademais, os textos de Clarice, poéticos e filosóficos, traziam aquilo que a autora tinha como espiritualidade, que a inquietava e a colocava em busca. Segundo Olga Borelli, secretária e amiga da autora, Lispector, "sem qualquer vinculação explícita, dava a impressão de sempre se achar em estado de questionamento: Deus, morte, matéria, espírito, eram objeto de interrogação, de perplexidade, que nem em conversas ela deixava de expressar". (BORELLI, 1981, p.18)

Podemos afirmar que Clarice Lispector busca a essência do ser: salienta a afetividade, o sensível, a força da vida que impulsiona uma existência mais plena. Para Elayne Bione, citada por Chaves (2012, p.301) "mesmo tendo se iniciado como escritora numa época em que os romancistas brasileiros estavam voltados para a literatura regionalista ou de denúncia social, Clarice enfoca em seus textos o ser humano em suas angústias e questionamentos existenciais".

Clarice mostra que através da literatura é possível dar poder a quem é oprimido, pois ela acredita que através de suas obras pode dar voz ao calado, e a palavra é sempre poder. "Já vi muita coisa no mundo. Uma delas, e não das menos dolorosas, é ter visto bocas se abrirem para dizer ou talvez apenas balbuciar, e simplesmente não conseguirem. Então eu quereria às vezes dizer o que elas não puderam falar". (LISPECTOR, 1999, p. 112)

Desta forma, com delicadeza, profundidade, coerência e lucidez, Clarice Lispector faz uso das palavras para torná-las ação, torná-las logos, torná-las vida e assim mover 
o leitor a também agir, refletir e viver. Enfim, conforme apresenta Berta Waldman (1983, p.89) sobre os textos de Clarice: "se quisermos saber o que diz o seu texto, devemos interrogar também o silêncio. Não o silêncio que se situa antes da palavra e que é um querer dizer, mas o outro, o que fica depois dela e que é um saber que não pode dizer a única coisa que, de fato, valeria a pena ser dita". (1983, p. 89)

\section{A Hora da Estrela}

A Hora da Estrela é a última publicação em vida de Clarice. Nessa obra, a autora se traveste de Rodrigo S. M. para assumir o desafio de expor a história da menina Macabéa e assim dar rosto a uma vida vazia, sem sentido, apagada por um mundo trágico, caótico e opressor. Para Guidin (1998, p.52) “o narrador vai privando Macabéa de insígnias tradicionais da feminilidade. Rodrigo a narra despojando a personagem de mecanismos de integração social, de instrumentos de sedução e de relações amorosas. Macabéa nada sabe de si nem do meio em que vive".

Rodrigo é o alter ego de Clarice. "O narrador da A Hora da Estrela é Clarice Lispector, e Clarice Lispector é Macabéa tanto quando Flaubert foi Madame Bovary". (NUNES, 1989, p. 169) Através desses personagens, a escritora exprime seu próprio pensamento, o mais interior daquilo que ela é, daquilo que ela sente.

Pensar é um ato. Sentir é um fato. Os dois juntos - sou eu que escrevo o que estou escrevendo. Deus é o mundo. A verdade é sempre um contato interior inexplicável. A minha vida a mais verdadeira é irreconhecível, extremamente interior e não tem uma só palavra que a signifique. (LISPECTOR, 1998, p. 18)

Alguns classificam A Hora da Estrela como um romance, outros como uma novela. Independentemente do estilo literário, essa obra é uma denúncia social. Desvela a situação de tantas pessoas que têm as suas vidas apagadas e exploradas por um sistema econômico, político e social cada vez mais injusto e cruel.

Em A Hora da Estrela, Clarice questiona e intervém na realidade. "A reflexão sobre o projeto ficcional em A Hora da Estrela será o meio pelo qual denuncia as máscaras sociais que encobrem a crise fundamental do indivíduo, alienado de si em rígidos papéis sociais". (LISPECTOR, 1998, p. 10)

Segundo Clarice Fulkeman ${ }^{1}$ um artista sensível percebe a sua realidade. Clarice reflete sobre o ser humano inserido em uma estrutura social que segrega os indivíduos entre si. "Em A Hora da Estrela este empreendimento assume uma ousadia e uma profundidade inusitadas. $\mathrm{O}$ escritor solta as amarras e vai até o fundo do poço: as origens do ser e as contradições da sociedade em que vive. (LISPECTOR, 1998, p. 7)

A Hora da Estrela pode ser como uma coroação de uma trajetória. Escrita à beira da morte da autora, aponta para os "sinais mais explícitos de uma maneira de ser, de uma voz que os vários narradores, na verdade Clarice Lispector, tateiam nas cartas, nos apontamentos e nos textos literários". (ARÊAS, 2005, p.74)

Desta forma podemos entender que A Hora da Estrela é uma das principais obras-primas de Clarice Lispector. A intensidade de sua narrativa, a riqueza de detalhes e ao mesmo tempo a profundidade com que expunha o drama da existência conquistam e movem leitores há décadas. É um clássico, foi transformado em filme, teve diversas edições e ainda hoje muito diz sobre o homem na contemporaneidade.

\footnotetext{
${ }^{1}$ Professora de Literatura Brasileira da Pontifícia Universidade Católica do Rio de Janeiro. Escreve a Apresentação de A Hora da Estrela.
} 


\section{Michel Henry}

Clarice Lispector tem como contemporâneo o filósofo Michel Henry (1922-2003). Embora atuando em lugares diferentes e de formas distintas, ambos olham para a realidade, percebem seus problemas e buscam refletir o seu contexto.

Henry, tal como Clarice, é um cidadão do mundo: nasceu no Vietnã, cresceu na Indochina e formou-se na França. Esse filósofo lecionou em diversas cidades onde divulgou as suas ideias. Assim como a escritora brasileira, também propôs um novo modo de pensar.

Através da fenomenologia, Michel Henry busca entender o contexto da segunda metade do século XX. Tempos de muitas crises e mudanças. Inserido numa Europa em construção após a II Guerra Mundial, Henry busca uma essência ideal de mundo que se afaste das ideologias científicas, biológicas e psicológicas.

Assim, Henry vai aprofundando a sua intuição associando a essência do mundo a termos "como 'Vida' ou 'Energia vital'. Henry apresenta em suas obras dois movimentos que formam o seu pensamento: a crítica à filosofia tradicional e a proposta de um método fenomenológico de investigação da vida no advir de si mesma como páthos" (PRASERES, 2014, p.244)

Desta forma, Henry surge como uma voz profética dentro do pensamento filosófico, pois apresenta outra forma de pensar que vai além daquilo que simplesmente aparece aos olhos do mundo em sua objetividade. Ele parte para uma fenomenologia que leve em consideração aquilo que é invisível, mas ao mesmo tempo presente em toda existência.

\section{A Fenomenologia da Vida}

Michel Henry percebe o que também Clarice aponta em seus escritos: o mundo se tornou opaco, caótico e raso. A vida é ocultada por uma ideologia e uma matriz de pensamento que lida somente com o aspecto externo, objetivado com o "pôr-de-fora".

Partindo desse pressuposto, Michel Henry acredita que a fenomenologia histórica iniciada por Husserl (1859-1938), embora tenha a pretensão de buscar a essência dos fenômenos, ficou indeterminada, restrita àquilo que aparece. "A Vida real, concreta, invisível, permaneceu, em Husserl, num anonimato inultrapassável" (ROSA, 2015, p. 72)

No entanto, na concepção henryeriana: "o aparecer não se limita absolutamente a fazer aparecer o que aparece nele; ele mesmo deve aparecer enquanto aparecer puro. Com efeito, nada apareceria jamais ao seu aparecer se não aparecesse a ele mesmo e antes de tudo" (HENRY, 2014, p. 42)

Para Henry, aparecemos a nós mesmos antes de aparecermos no mundo. O "pôr-de-fora" não se dá nos objetos, é algo mais originário. O conteúdo real do mundo sensível decorre de uma impressão exclusiva, ou seja, o conteúdo real do mundo é uma revelação original, primitiva, impressional', sensual". (HENRY, 2014, p. 72)

Henry faz uma inversão da fenomenologia histórica. Sua proposta é de uma filosofia que ressalte o fenômeno originário: em que consiste, em como aparece em si mesmo e, antes de tudo, em seu autoaparecer. Ele quer chegar efetivamente ao mais original das "coisas mesmas".

Para ele, o que vem antes de tudo, com efeito, é o próprio aparecer da vida em sua fenomenalização originária, em sua autorrevelação em sentido radical. A vida para Henry se experimenta num páthos, uma impressão sofredora e fruidora.

Para Henry a vida é uma matéria impressional que se "experimenta a si mesma impressionalmente e não cessa de fazê-lo, uma autoimpressionalidade vivente

\footnotetext{
${ }^{2}$ Termo utilizado por Henry para enfatizar a importância da impressão afetiva da vida.
} 
(...) É somente porque pertence a uma carne, porque traz em si essa autoimpressionalidade patética e vivente que toda impressão concebível pode ser o que é. (HENRY, 2014, p. 92)

A Vida para Henry é da ordem da subjetividade e da sensibilidade. É uma afetividade transcendental, imanente. "A vida se manifesta como afeto, este é primário. Vida é affectus, é um Si dado a si mesmo na vida, e apenas provado nesta. A partir deste sentir primitivo se desenvolvem a consciência, o pensamento, a linguagem, a memória e as demais características e ações humanas". (PRASERES, 2014, p. 246)

A fenomenologia da vida é uma intuição de Michel Henry que busca portanto, resgatar a vida como o mais real e originário da existência humana e portanto da ação do homem. Para ele: "A vida não pode se distanciar da vida". (HENRY, 2012, p. 87)

Na concepção henryeriana "a essência originária do agir é o movimento contínuo da Vida na sua autofruição. É por isso que a Vida é para si mesma, imediatamente, o seu Próprio Mandamento e não precisa de injunções e de preceitos éticos exteriores e separados de si". (ROSA, 2015, p. 13)

\section{Macabéa e o ocultamento da Vida Originária}

Inserida "em estado de emergência e de calamidade pública", Clarice Lispector coloca no centro do palco uma imigrante que vive desajustada no Rio de Janeiro: o fenômeno Macabéa. Diferentemente da concepção de humanidade em que Clarice acredita e que Michel Henry quer recuperar, Macabéa é o paradigma das vítimas do mundo que só são vistas a partir de sua exterioridade.

Fora de qualquer padrão de beleza, o estereótipo de Macabéa é apresentado em A Hora da Estrela conforme o olhar do mundo moderno coisificador. A escritora a descreve "de ombros curvos como os de uma cerzideira, com o corpo cariado. Era um 'acaso, um feto jogado na lata de lixo embrulhado em um jornal'". (LISPECTOR, 1998, p.12)

Para os olhos objetivadores do mundo moderno, que não levam em consideração a vida em sua imanência, Macabéa é mais um alguém que nasceu com "maus antecedentes e agora parecia uma filha de um não-sei-o-quê com ar de se desculpar por ocupar espaço".

A descrição da jovem traz as marcas da subjugação do homem em meio ao contexto moderno: Macabéa traz machas em seu rosto, que em "Alagoas chamavam-se "panos", diziam que vinham do fígado". Marcas de um "fel" difícil de digerir. As manchas de Macabéa são as marcas impostas pelo sistema que impedem a jovem alagoana a perceber o mais profundo de si mesma.

A moça é apresentada, também, como "um pouco encardida pois raramente se lavava". Sua presença incomoda os outros: "uma colega de quarto não sabia como avisar-lhe que seu cheiro era morrinhento". Clarice continua: "ninguém olhava para ela na rua, ela era café frio". (LISPECTOR, 1998, p.28) A existência roubada de Macabéa era fria, sem brilho, sem cor.

Macabéa desvela a angústia daqueles que vivem "num limbo impessoal, sem alcançar o pior nem melhor. Ela somente vive, inspirando e expirando, inspirando e expirando". (LISPECTOR, 1998, p.25). Sua vida, seus sentimentos e sua afeição não são levados em conta, embora seja essa vida que dá origem a toda a existência dessa mulher.

Macabéa, em tudo e por tudo, é o oposto do herói épico. Sua trajetória e vida aponta para a inviabilidade dos grandes feitos na sociedade moderna. Retomando um conceito do crítico alemão Walter Benjamin, pode-se afirmar que ela sequer teve uma experiência de vida que a memória um dia pudesse ou soubesse resgatar. (LISPECTOR, 1998, p.12)

Clarice Lispector, através de Macabéa, mostra o quanto o esquecimento da vida torna o homem sem sentido e vazio. 
[Macabéa] era incompetente. Incompetente para a vida. Faltava-lhe o jeito de se ajeitar. Só vagamente tomava conhecimento da espécie que tinha de si em si mesma. Se fosse criatura que se exprimisse diria: o mundo é fora de mim, eu sou fora de mim. (LISPECTOR, 1998, p.26)

\section{Ciência e Técnica: barbárie contra a vida}

Henry aponta que a origem desse obscurecimento da vida em seu aspecto afeccional, imanente e patético, remonta a Galileu Galilei, que declarou ilusório o conhecimento do mundo sensível. Para um dos "pais" da idade moderna, o universo real não pode ser conhecido pela sensibilidade, mas apenas pela geometria e pela matemática. Ele relega, portanto, todos os outros saberes a sua insignificância.

O pensamento de Galileu elimina da realidade toda sensibilidade, impressões, emoções, desejos e paixões, pensamentos, em suma, toda a nossa subjetividade. Essa concepção não altera somente o plano teórico. Henry aponta que a redução galileana moldou o nosso mundo, delimitando uma nova época da história.

A modernidade resulta de uma decisão intelectual formulada com clareza (...) de compreender, à luz do conhecimento geométrico-matemático, um universo doravante reduzido a um conjunto objetivo de fenômenos materiais e, mais do que isso, a decisão de construir e organizar o mundo baseando-se de maneira exclusiva sobre esse novo saber e sobre os processos inertes que permitem dominá-lo. (HENRY, 2012, p. 114)

Em sua denúncia, o filósofo afirma que a ciência, como toda ação do homem, é uma forma de vida, pois toda construção humana tem sua origem na vida. Ao abstrair a sensibilidade, as ciências e o pensamento moderno abstraem a vida, a rejeitando e ignorando-a.

A ciência, quando pretende ser a detentora da verdade, volta-se contra aquilo que lhe dá origem, recusa dar à vida todo valor e contesta até mesmo a sua existência. A ciência é "uma vida que se nega a si mesma, a autonegação da vida, este é o acontecimento crucial que determina a cultura moderna como cultura cientifica". (HENRY, 2012, p. 105)

Com o desenvolvimento das ciências do Séc. XVII surge a técnica. O tecnicismo desenvolvido nos últimos anos, por não levar em consideração a vida, diminuiu o valor do homem dentro da sociedade.

Em nome do progresso, as comunidades humanas acostumaram-se a descartar pessoas, culturas e valores. Para Henry, os homens afastados da verdade da vida mergulham nos enganos, "nos prodígios em que a vida é negada, ridicularizada, troçada, simulada, ausentes".

Diante de um sistema capitalista, onde o poder pertence àquele que possui mais recursos econômicos, Henry afirma que "os homens são substituídos por abstrações, entidades econômicas, lucros e dinheiro. Os homens são tratados matematicamente, informaticamente, estatisticamente, contados como animais, sendo tidos em menor apreço do que estes". (HENRY, 2012, p. 277)

Nas personagens de Macabéa, de suas companheiras de quarto e de Glória (companheira de trabalho da protagonista), Clarice Lispector evidencia o mundo moderno com sua técnica e economia fechadas em si mesmas, que colocam o homem como simples engrenagens de um sistema desumanizador.

Como a nordestina, há milhares de moças espalhadas por cortiços, vagas de cama num quarto, atrás de balcões trabalhando até a estafa. Não notam sequer que são facilmente substituíveis e que tanto existiram como não existiriam. Poucas se queixam e ao que eu saiba nenhuma reclama por não saber a quem (LISPECTOR, 1998, p.19) 
A crise do homem também é retratada na personagem de Olímpico, imigrante nordestino por quem Macabéa se apaixona: tem dentes de ouro, pois isso fazia sentir-se rico. Sonhava em ser deputado embora dormisse de graça numa guarita de obra por camaradagem do vigia. A vida de Olímpico apresenta a realidade trágica da humanidade vítima da técnica. Nesse contexto os homens buscam interpretar papéis que os ajudam amenizar o seu próprio sofrimento, a diminuir a dor de terem as suas vidas obscurecidas.

Embora fosse operário, Olímpico, mesmo sem notar, chama-se de operário. Seu "trabalho consistia em pegar barras de metal que vinham deslizando de cima da máquina para colocá-las embaixo, sobre uma placa deslizante. Nunca se perguntara por que colocava a barra embaixo". (LISPECTOR, 1998, p.39)

A técnica com vistas em si mesma impediu o homem de colocar em prática a energia vital que se apresenta no corpo e se expressa no trabalho e nas relações. Essa energia aprisionada, recalcada, torna o homem insuportável a si mesmo.

Passava o resto do dia representando com obediência o papel de ser. (...) A datilógrafa vivia numa espécie de atordoado nimbo, entre céu e inferno. Nunca pensara em "eu sou eu". Acho que julgava não ter direito, ela era um acaso. (LISPECTOR, 1998, p.33)

\section{A morte da cultura}

Impedido de direcionar tal energia para um fazer que eleve as suas potencialidades, o homem passa a viver numa letargia total em relação ao seu contexto e à realidade em que está inserido, matando a cultura e, portanto, obscurecendo a vida.

Henry dá muita importância para a cultura, pois acredita que ela tem uma função prática de autodesenvolvimento das potencialidades que compõem a vida. É a "autorrevelação da vida em seu autocrescimento". No entanto, a cultura é fortemente influenciada pela mídia, esta que por sua vez está inserida também num mundo técnico-científico que busca somente o lucro, o poder e não leva em consideração a vida.

Clarice apresenta a "alegria de Macabéa": a Rádio Relógio, que dava "hora certa e cultura", e nenhuma música, só pingava em som gotas que caem - cada gota de minuto que passava. E, sobretudo, esse canal de rádio aproveitava intervalos entre as tais gotas de minuto para dar anúncios comerciais - ela adorava anúncio". (LISPECTOR, 1998, p.34)

Atenta a seu tempo, Lispector insere no enredo a relação de Macabéa com a mídia e com a cultura. Ressalta quão vazia e sem sentido é a mídia. Mesmo que aborde temas importantes da vida, em nada ajuda no desenvolvimento de suas potencialidades.

Sem noção do impacto da realidade em sua vida Macabéa diz "A rádio Relógio diz que dá a hora certa, cultura e anúncios. Que quer dizer cultura? É que muita coisa eu não entendo bem. O que quer dizer "renda per capita? " (LISPECTOR, 1998, p.43)

\section{A Ética da Vida: A Hora de Estrela}

Tal como Henry com sua proposta de libertação de uma ideologia coisificadora e desumanizadora através da fenomenologia da vida, Clarice aponta para libertação de Macabéa.

No enredo, em meio ao sofrimento e angústia da existência, a nordestina consegue ter esperança. Ainda que num primeiro momento parecesse que Macabéa cairá em um novo golpe da vida, a ida à cartomante significa o início de um novo horizonte para a protagonista. 
O carinho e atenção da cartomante fizeram com que finalmente Macabéa começasse a perceber que há nela uma vida, uma vida que sempre pulsara mas que diante de tantas opressões não percebia que tinha. Ela enfim estava feliz, pois "pela primeira vez ia ter um destino. Madama Carlota era um ponto alto na sua existência". (LISPECTOR, 1998, p.62)

Macabéa passa a perceber que em seu interior, e somente nele, há uma pulsão, um movimento que dá origem a toda a sua ação, a toda a sua existência.

Sentia em si uma esperança tão violenta como jamais sentira tamanho desespero. Se ela não era mais ela mesma, isso significava uma perda que valia por um ganho. Assim como havia sentença de morte, a cartomante lhe decretara sentença de vida. (LISPECTOR, 1998, p.64)

Ao final de sua trajetória, feliz e realizada por ter um futuro, Macabéa é atropelada. A morte para a "vida" antiga, essa vida superficial e vazia, é iminente. Macabéa, destituída de qualquer interferência externa, consegue finalmente perceber a si mesma, sentir em si aquilo que vem antes de tudo, o mais originário de seu próprio ser.

Tanto estava viva que se mexeu devagar e acomodou o corpo em posição fetal. Grotesca como sempre fora. Aquela relutância em ceder, mas aquela vontade o grande abraço. Ela se abraçava a si mesma com vontade do doce nada. Era uma maldita e não sabia. Agarrava-se a um fiapo de consciência e repetia mentalmente sem cessar: eu sou, eu sou, eu sou. Quem era, é que não sabia. Fora buscar no próprio profundo e negro âmago de si mesma o sopro de vida que Deus nos dá. (LISPECTOR, 1998, p.67)

Michel Henry, ao propor a inversão da fenomenologia, sugerindo a fenomenologia da vida, convida também a uma morte, à morte para uma ideologia e concepção de vida focada somente no exterior e no superficial.

A afirmação das ciências como fim da vida não legitima qualquer apreciação pejorativa visando a desqualificar a ciência, nenhuma condenação. "É somente quando o domínio da ciência é compreendido como o único domínio de ser realmente existente, e se vê disposto a rejeitar para o campo do não ser ou à aparência da ilusão aquele em que se mantém a vida e sua cultura, que o filósofo tem que intervir". (HENRY, 2012, p.49)

O convite de Henry é para mergulharmos numa vivência carnal, pois para ele a fenomenologia da vida se dá numa carne sensível. O homem e toda a sua ação e existência são da ordem do corpo de carne. "É dessa corporeidade original que deriva as capacidades fundamentais, a de ser uma força e de agir, de receber hábitos, de se lembrar" (HENRY, 2012, p.12)

Essa reflexão desencadeia a questão ética. Na concepção henryeriana "A vinda a si da vida (...) é identicamente o movimento por meio do qual nós nos comportamos, o que somos, o que fazemos (...) fornece todavia tudo o que ela é e tudo o que ela faz, tornando-se assim nossa própria ação. " (HENRY, 2012, p.156)

É a vida que confere valor às coisas. Os valores fundamentais estão implicados nas primeiras experiências que a vida tem de si mesma. (Faz parte de uma) autoafirmação, a qual se confunde com o movimento da vida em seu contínuo esforço para perseverar em seu ser e para crescer. Semelhante movimento constitui a teleologia imanente da vida, na qual se enraíza toda ética possível. Não a ética teórica ou normativa, que representa para si fins e valores, mas a ética original ou, antes, o próprio ethos, ou seja, o conjunto de processos indefinidamente recomeçados nos quais a vida realiza sua essência. (HENRY, 2012, p.149)

O ser para Michel Henry tem a sua origem e o seu fim na vida fenomenológica. Desta forma a ação humana, a ética do homem devem se inspirar nesse pressuposto. Ainda que as inovações científicas e tecnológicas tenham contribuído positivamente em muitos aspectos da vida humana, essa ideologia não é capaz de abarcar toda a existência do homem. 
A ética proposta por Henry reconhece a vinda da vida. Na vida a ordem não é exterior, a ação não está separada do homem. "O habitat do agir é a Vida. Só na Vida se pode contatar com o agir, só nela há as modalidades do viver". (HENRY, 2012, p.185)

\section{Considerações Finais}

Em A Hora da Estrela, Clarice Lispector coloca no palco a dramática história de Macabéa, e assim busca fazer uma denúncia social. A escritora evidencia como o homem tem sua vida obscurecida por um mundo injusto e opressor.

Michel Henry, assim como Lispector, também identifica o trágico da vida humana que foi obnubilada pelo saber científico e pela técnica, que, fechados em si mesmos enxergam o homem apenas como uma peça na grande engrenagem do mundo capitalista.

A autora da A Hora da Estrela consegue dar a Macabéa, ao personagem escritor e ao leitor, a possibilidade de perceber-se, de notar a vida que está no mais interior de nosso ser e que não pode ser representada no mundo, pois este não consegue enxergá-la. Em seus escritos, Clarice ajuda o leitor a paralisar a sua vida cotidiana na imediatez de onde se está e lhe possibilita um mundo de possibilidades. No mundo ficcional, abrem-se novas capacidades desconhecidas de nós mesmos.

Através da morte para o mundo de Macabéa, Clarice Lispector move o leitor a pensar na sua própria vida, na sua própria existência. Convida o leitor a mergulhar em seu interior e perceber a vida que pulsa dentro de cada um.

Clarice atinge o leitor de forma poética (até trágica), convida a fazer a inversão fenomenológica de sua vida e de sua forma de ver a existência. A escritora brasileira, em outras palavras, conduz a uma fenomenologia da vida, a mesma proposta por Henry.

Assim, Clarice evidencia em seus escritos que é possível ter um pensamento a partir da realidade brasileira. Mostra que existe no Brasil uma filosofia genuína, que a partir de nosso contexto, de nossa vida, busca uma reflexão mais aprofundada da realidade.

Michel Henry e Clarice Lispector, mesmo de formas diferentes, dizem a mesma coisa: denunciam a barbárie de uma visão limitada da existência, buscam a essência da vida.

A obra e o pensamento de ambos convidam a um viver mais pleno, verdadeiramente ético, que leva em conta aquilo que é mais original: a vida em seu páthos, em sua imanência, em seu autoaparecer.

Clarice e Henry convidam o leitor a recuperar a vida originária e pô-la em evidência. Exalta aqueles que leem suas obras a não desperdiçar a existência e definitivamente viver a Hora da Estrela. Pois assim como a vida é inerente à condição humana, Macabéa representa todos nós.

Correspondência: João Elton Jesus. Faculdade de Filosofia e Teologia - FAJE, Av. Dr. Cristiano Guimarães 2127, CEP: 31710-560, Belo Horizonte, Minas Gerais, Brasil. E-mail: joao.elt@gmail.com Conflito de interesses: Nenhum.

Todos os autores leram e aprovam a versão final submetida a revista Em curso. 


\section{Bibliografia}

ARÊAS, V. Clarice Lispector com a ponta dos dedos. São Paulo: Schwarcz, 2005. In SPINELLI, D. A posição do narrador, Rodrigo S. M., em a Hora da Estrela, de Clarice Lispector. Disponível em: <http: / / www4.pucsp. br/revistafronteiraz/numeros_anteriores/n1/download/Artigo_de_Daniela_Spinelli.pdf $>$. Acesso em: 15.fev.2016

BORELLI, O. Clarice Lispector: esboço para um possível retrato. Rio de Janeiro, Nova Fronteira, 1981.

BOSI, A. História concisa da Literatura Brasileira. São Paulo: Cultrix, 2001.

CHAVES, A. C. Clarice Lispector e o fundamento do direito de punir. Revista dos Estudantes de Direito da UnB, v.10, 2012, p. 299-315. Disponível em: < http:/ / periodicos.unb.br/index.php/redunb/article/ viewFile/7106/5602>. Acesso em: 16.jul.2016.

CAMPEDELLI, S. Y. ABDALA Jr., B. Tempos da Literatura Brasileira. São Paulo: Editora Ática, 2001.

HENRY, M. A barbárie. Tradução Luiz Paulo Rouanet. São Paulo: É Realizações, 2012.

Encarnação: uma filosofia da Carne. Tradução: Carlos Nougué. São Paulo: É realizações, 2014.

Eu sou a verdade. Tradução: Carlos Nougué São Paulo: É Realizações, 2015.

LISPECTOR, C. A Hora da Estrela. São Paulo: Rocco, 1998.

A descoberta do mundo. $2^{\text {a }}$ ed., Rio de Janeiro: Rocco, 1999

NUNES, B. O Drama da Linguagem: Uma leitura de Clarice Lispector. São Paulo: Ática, 1989.

O mundo de Clarice Lispector. Manaus: Edições Governo do Estado do Amazonas, 1966.

PRASERES, J. A fenomenologia da vida: apontamentos sobre afetividade e não-intencionalidade para a fundamentação de uma ética no pensamento de Michel Henry. Griot - Revista de Filosofia, v.10, n.2, dezembro/2014-Disponível em: <http://www2.ufrb.edu.br/griot/images/vol10-n2/16.pdf>. Acesso em: 03. jul.2015.

ROSA. J.M.S.O Ethos da ética. Disponível em: <http://www.lusosofia.net/textos/jose_rosa_o_ethos_ da_etica_fenomenologia_michel_henry.pdf>. Acesso em: 02.jul.2015.

ROSENBAUM, Y. A ética na literatura: leitura de "Mineirinho", de Clarice Lispector. Disponível em: < http:/ / www.scielo.br/pdf/ea/v24n69/v24n69a11.pdf >. Acesso em: 02.jul.2015.

“Clarice Lispector quer desmontar as máscaras e conhecer o que há por trás delas". Entrevista concedida à IHU On-line, Ano VII, 16.07.2008. Disponível: < http:/ / www.ihuonline.unisinos.br/index. php?option=com_content\&view=article\&id=1141\&secao=228> . Acesso em: 01.jul.2016.

SILVA, J. C. Corpo e transgressão em Perto do Coração Selvagem: as vastas interpretações de Joana. Disponível em: <http:/ /dspace.bc.uepb.edu.br/jspui/bitstream/123456789/4677/1/PDF\%20-\%20Juliane\%20 C\%C3\%A2ndido\%20da\%20Silva.pdf>. Acesso em: 04.jul.2015.

VASQUEZ, P. K. Clarice por Clarice. Disponível em: <http:/ / www.claricelispector.com.br/autobiografia. aspx> Acesso em: 01.jul.2015.

WALDMAN, Berta. Clarice Lispector. SP: Brasiliense, 1983. 